\title{
Cultura popular e educação: um estudo sobre a Capoeira Angola
}

\begin{abstract}
RESUMO: Este artigo é parte de minha tese de doutorado em Ciências Sociais aplicadas à Educação (Unicamp), que se propôs investigar as formas com as quais a cultura popular articula todo um vasto campo de conhecimentos e saberes, bem com as formas de transmissão desses saberes através de algumas categorias, que elegemos como base para essa tarefa, quais sejam: a memória, a oralidade, a ancestralidade, a ritualidade e a temporalidade. Para realizarmos tal tarefa, elegemos a Capoeira Angola, manifestação da cultura afro-brasileira das mais significativas, como campo privilegiado de estudo, na tentativa de buscar os seus sentidos e significados.

PALAVRAS-CHAVE: Cultura popular. Capoeira Angola. Educação não-formal.
\end{abstract}

Pedro Rodolpho Jungers Abib

Professor Adjunto da Faculdade de Educação da UFBA

pedrabib@ufba.br

\section{Introdução}

Assim como em todas as partes do mundo no Brasil podemos também perceber o quanto esse processo de homogeneização cultural causado pela globalização, vem modificando os comportamentos, inaugurando novas formas de expressão e compreensão do mundo, fortemente influenciadas por uma indústria cultural que consegue estabelecer-se enquanto referência hegemônica e determinante de gostos e preferências, onde muito de nossas tradições artístico-culturais vão sendo, pouco a pouco, substituídas por um tipo de produto pasteurizado, feito para um consumo cultural ligeiro e superficial voltado para um mercado volátil e pouco exigente qualitativamente.

Entretanto, contraditória e paralelamente a esse processo de canibalismo cultural em curso na nossa sociedade, estamos assistindo a um fortalecimento de determinadas formas culturais e manifestações da nossa cultura popular que até um período recente de nossa história praticamente agonizavam. Tais expressões culturais experimentam hoje uma revitalização, um reconhecimento e uma revalorização por parte de setores cada vez mais amplos da sociedade - incluindo a mídia - deixando perplexos até mesmo aqueles incansáveis defensores da preservação de nossas tradições populares, que talvez não fossem capazes de imaginar, nem os mais otimistas, que esse passado moribundo pudesse fazer-se vigorar com tanta força no presente. 
Nesse contexto, trazemos aqui a Capoeira Angola, que como outras manifestações da cultura popular, experimenta no momento atual, após um período de declínio e quase desaparecimento, um processo de revitalização que tem sido notado não somente no território brasileiro, como também em várias outras partes do mundo.

Este texto pretende analisar tal processo partindo de uma abordagem em que buscaremos compreender o significado que possui o fenômeno de ressurgimento dessa tão significativa manifestação da cultura popular, enquanto um rico processo de educação não-formal, e também de se conceber o passado como força instauradora, capaz de atualizar-se no presente, fazendo vigorar uma memória que alimenta esse presente, abrindo perspectivas para uma ação construtiva do futuro.

\section{A memória enquanto força instauradora}

Vivemos um período histórico em que a valorização exacerbada do tempo presente não nos permite olharmos o passado, a partir de uma ritualidade que se apresenta enquanto força instauradora, mas como algo passado e incapaz de fazer sua aparição e irromper no presente. O poder de revelação e de fulguração foi lançado unicamente para o futuro. Todas as perspectivas de transformações e mudanças, a espera por uma vida melhor, as promessas por dignidade estão depositadas num futuro...que nunca chega. O presente então, eterniza-se. Alastra-se ao passado e sobrepõe-se ao futuro.

Essa idéia de repetição do presente constitui-se como base para uma teoria que tem seduzido um número cada vez maior de intelectuais antes engajados num projeto histórico de transformação: a teoria do fim da história. Ao realizar uma crítica a essa teoria, Boaventura de Sousa Santos (1997) afirma que o grão da verdade da teoria do fim da história está em que ela é o máximo de consciência possível de um discurso falacioso de uma burguesia internacional que vê, finalmente, o tempo transformado na repetição automática e infinita do seu domínio. Segundo o autor, o outro lado do fim da história é o slogan da celebração do presente, tão cara às versões capitulacionistas do pensamento pós-moderno. Dessa forma, tanto o passado quanto o futuro parecem vazios de sentido, e tal incapacitação do futuro não abre qualquer espaço para a capacitação do passado. A humanidade sofre hoje de uma 
amnésia paralisante: esquecemos de saber olhar o passado como uma força instauradora. Impedimos assim, que essa força possa vigorar no presente e, desse modo, interferir no futuro.

O passado deve ser visto, segundo Santos (1997), como um recurso capaz de irromper num momento de perigo em socorro dos vencidos. O autor cita Walter Benjamin para quem: "Articular o passado historicamente não significa reconhecê-lo como 'verdadeiramente foi'. Significa apoderarmo-nos de uma memória tal como ela relampeja num momento de perigo" e afirma que a capacidade de redenção do passado reside nesta possibilidade de emergir inesperadamente num momento de perigo;, como fonte de inconformismo. Nesse frutífero diálogo com Benjamin, Santos identifica o atual período histórico em que vivemos como um momento de perigo; e dessa forma, não podemos voltar a pensar a transformação social e a emancipação sem reinventarmos o passado, tal qual propôs o pensador alemão, na época em que o nazismo assolava o continente europeu. Benjamin dizia que "o inconformismo dos vivos não existe sem o inconformismo dos mortos, já que nem estes estarão a salvo do inimigo se esse vencer". Desde essa perspectiva, o passado não pode ser visto como algo inerte, cristalizado no tempo, algo que foi, mas como algo vivo, que vigora e que tensiona com o presente, abrindo possibilidades futuras.

Trazemos aqui a contribuição do filósofo alemão Martin Heidegger (1995), que busca compreender a noção do tempo desde a perspectiva da articulação entre suas instâncias - passado, presente e futuro - como superação da lógica da linearidade temporal que impera no ocidente. A concepção heideggeriana de tempo não se atrela à perspectiva tradicional na qual, passadopresente-futuro se articulam numa seqüência retilínea de acontecimentos, sendo o presente ("o que é") considerado a dimensão temporal privilegiada, na medida em que o passado ("o que não é mais") é visto como algo que ficou para trás, e o futuro ("o que ainda não é") como algo impreciso, indeterminado, vazio. Para Heidegger, o tempo é pensado como uma unidade destas três dimensões temporais. Se, porém, este filósofo nos fala de unidade temporal, é porque não concebe o tempo como um agrupamento de "partes" isoladas: presente, passado, futuro; ao invés, pensao como uma unidade centrífuga que, num movimento de ex-centração, se temporaliza. 
Heiddeger concebe a "articulação" das dimensões chamadas de passado-presente-futuro, de modo diferente da caracterização tradicional. Ao analisar a obra desse importante pensador alemão, Caroline Ribeiro (2000) afirma que, para ele, o presente, enquanto atualidade do que é, está necessariamente em contínua tensão com o passado (compreendido como o que vigora por já ter sido), ou seja, o presente é perpassado pelo passado que o força a atualizar-se. E neste insistir do que ainda vigora no presente abre-se o horizonte a ser ultrapassado no porvir (futuro). Deste modo, a projeção do futuro, ao acontecer no presente perpassado pelo passado, realiza-se num novo presente, que, por sua vez, será novamente determinado pelo vigor de ter sido e, nesta tensão, abrirá uma nova projeção de possibilidades futuras, e assim sucessivamente. Abandona-se então, a concepção linear de tempo, encarando-o desde uma outra ótica, a circular. A partir da perspectiva circular do tempo, o passado não é algo que se esgotou mas, algo vigente que guarda e aguarda um sentido. Segundo este filósofo, a metafísica - que nasce com Platão e Aristóteles - aniquila essa noção da circularidade do tempo ao impor a lógica linear como única possibilidade de pensá-lo e concebê-lo.

A riqueza de significações presente na nossa cultura popular nos permite traçar paralelos com algumas das teorias aqui citadas, na tentativa de compreender a função que essas manifestações culturais exercem não só no imaginário popular de uma forma mais generalizada, como também no próprio cotidiano do grupo a que estão mais diretamente vinculadas. Nesse sentido é que trazemos, aqui, a análise da Capoeira Angola, enquanto uma manifestação extremamente importante para o universo da cultura afro-brasileira e que se vincula ao próprio processo civilizatório brasileiro, sobretudo no que diz respeito ao período escravocrata.

Elementos lúdicos e agressivos, dança e batalha, vida e morte, medo e alegria, sagacidade, música, brincadeira, ancestralidade e ritualidade constituem o universo da Capoeira Angola, que a caracteriza como uma manifestação cultural difícil de ser definida num único conceito. Essa riqueza de significações, quando devidamente contextualizada e historicizada, dá à Capoeira Angola uma identidade muito forte e profunda, construída através de todo um passado de luta por libertação, e sobretudo pela afir- 
mação de uma cultura que se recusa a ser subjugada, embora muito se tenha feito em nosso país para que isso se concretizasse (CASTRO; ABIB; SANTANA SOBRINHO, 2000).

Tendo a sua gênese num contexto extremamente violento, onde a luta pela liberdade e pela vida se fazia necessária, a Capoeira Angola traz na sua essência esse caráter de revolta contra todo um sistema desumano e opressor. É a autêntica manifestação de um grito por libertação que vem da alma de um povo subjugado, que se apega às suas raízes - e ao seu passado - para encontrar forças e continuar resistindo contra uma situação tão adversa. A rebeldia da Capoeira Angola reside no fato de que ela sempre foi uma contestação ao estabelecido. Ao inverter a lógica das coisas, quando fica de "pernas para o ar" subvertendo assim esse "olhar" para o mundo, o capoeirista exprime o sentido maior da dialética humana.

Quando numa roda de Capoeira Angola, os jogadores, antes do jogo, agacham-se em reverência, e no cantar de uma ladainha, invocam todo um passado de luta e sofrimento; quando se busca nesse momento de celebração, toda a memória e a tradição espiritual de um povo que segue resistindo a séculos de dominação; quando esse diálogo corporal se inicia expressando uma estética que remete a toda uma ancestralidade que incorpora referências rituais de um passado que continua vivo, tatuado no corpo de cada capoeirista, talvez possamos compreender um pouco melhor a noção de circularidade do tempo; talvez possamos sentir essa força instauradora de um passado que vigora a cada vez que os acordes de um berimbau ecoam como navalha cortando o ar. Berimbau que era utilizado nos primórdios da mãe África, como instrumento para conversar com os mortos. Mortos que são chamados para restituir a dignidade daqueles que insistem em se fazerem seus herdeiros.

Esse passado, tão presente numa roda de Capoeira Angola, vigora e denuncia, à medida que traz à tona tantos conflitos, permitindo dessa forma, uma melhor compreensão do presente, enquanto se traduz como indignação e inconformismo, assim como nos falou Benjamin. Nesse vigorar, abre as possibilidades para projeção de um futuro que já se faz germinado a partir da tomada de uma consciência coletiva sobre a historicidade dos processos das relações sociais, das quais esses sujeitos são protagonistas. Falamos de um processo de conscientiz-ação coletiva, 
pois se trata de uma consciência que abre concretas possibilidades de ação, enquanto construção de um futuro. Caracteriza-se, dessa forma, um rico processo de educação não-formal baseado nos saberes e nas tradições populares. Na roda de Capoeira Angola completa-se assim a noção da circularidade do tempo: passado, presente e futuro compreendidos enquanto unidade temporal.

É justamente nessa perspectiva que Santos (1997) propõe como nossa tarefa primordial neste início de milênio, a de reinventar o passado de modo que ele assuma a capacidade de fulguração, irrupção e redenção que Benjamin imaginou com grande presciência. "Para o materialismo-histórico", diz Benjamin citado por Santos (1997), "do que se trata é de reter uma imagem do passado tal qual ela aparece ao sujeito histórico, inesperadamente, no momento de perigo". Cabe aqui enfatizar que, ligada à idéia de passado como força instauradora, está a noção de enraizamento, que é segundo Ecléa Bosi (1987), um direito humano esquecido: todo homem tem uma raiz pela sua participação numa coletividade que conserva vivos alguns tesouros do passado e certos pressentimentos do futuro. Para a autora, o enraizamento não se alimenta de um passado idealizado nem de um futuro utópico, e à luz de Marx, cita um pensamento de Simone Weil, (apud BOSI, 1987, p.23) para quem:

O amor pelo passado não tem nada a ver com uma orientação política reacionária. Como todas as atividades humanas, a Revolução extrai toda a seiva de uma tradição. Marx o sentiu tão bem que fez questão de buscar a origem dessa tradição nas mais longínquas idades, fazendo da luta de classes, um princípio de explicação histórica [...] A oposição entre passado e futuro é absurda. O futuro não nos traz nada, não nos dá nada; nós é que, para construí-lo, devemos dar-lhe tudo, dar-lhe a nossa própria vida.

Ao analisarmos de uma maneira geral o processo de revitalização de muitas das tradições da cultura popular em curso na nossa sociedade, das quais trazemos o caso específico da Capoeira Angola, estamos buscando compreender esse fenômeno desde a perspectiva da circularidade do tempo, no qual a ritualidade presente nas pesadas vestimentas do guerreiro do Maracatu, no estampido agudo das matracas do Bumba-meuboi, nos versos de inspiração medieval dos repentistas nordestinos, nos sulcos esculpidos pelo tempo nos rostos das baianas 
vestidas de negro na festa de N.S. da Boa Morte ou nos passos lépidos do dançarino do Jongo, vem trazer à tona e fazer vigorar, um passado que não está, de forma alguma, cristalizado nalgum museu de folclore, nem muito menos agonizante num longínquo rincão do Brasil, mas insiste em fazer-se vigorar no presente, presentificar-se aqui e agora, enquanto memória que se traduz como força instauradora de um inconformismo capaz de transformar esse presente, abrindo e projetando novas possibilidades de futuro.

Em nosso entendimento, a função histórica que essas tradições populares - e a Capoeira Angola tem um especial significado nesse contexto - vêm cumprir, nesse momento em que vivem um processo de revitalização, experimentando um reconhecimento e uma revalorização por parte de setores cada vez mais amplos da sociedade, é justamente a de serem essa força instauradora de uma memória que retorna sistemática e ciclicamente, justamente num momento de perigo como tão bem nos lembrou Benjamin. Justamente quando a eternização do presente parece ser inevitável. Um presente que superficializa e banaliza a cultura de um povo, tornado-o assim desenraizado, desmemoriado e reificado por uma lógica que mercadoriza até mesmo as aspirações mais íntimas dos seres humanos. Obrigam-nos assim, a mudarmos até mesmo nossa identidade social: deixamos de ser cidadãos para tornarmo-nos consumidores. A memória assume então, neste momento histórico, uma importância e um significado cruciais, se quisermos pensar num projeto de transformação social, num projeto de restituição da capacidade de inconformismo a um povo aviltado em sua dignidade e alijado de sua consciência histórica.

\section{Cultura popular, escola e educação}

A educação formal em nosso país atravessa uma profunda crise e, sem entrar no mérito dos equívocos produzidos por políticas educacionais implementadas ao longo de várias décadas, é possível afirmar que ela não consegue garantir uma formação crítica, integral, qualificada e universalizada ao conjunto de mi1hões de brasileiros, em que a maioria está alijada desse direito fundamental, garantido em inúmeros tratados, estatutos, declarações e leis, funcionando, porém, apenas como letra fria sobre o papel. (CASTRO; ABIB, SANTANA SOBRINHO, 2000) 
Os códigos de valores presentes nos processos educativos envolvendo a cultura popular, por sua vez se diferenciam substancialmente daqueles privilegiados num processo formal de educação, mas são fundamentais para garantir a sobrevivência desses sujeitos numa realidade e num contexto ainda muito distante da escola formal, que não consegue apreendê-lo nem compreendêlo de forma mais profunda. O aprendizado sociocultural proporcionado, por exemplo, pela capoeira, fruto da vivência comunitária de crianças e jovens, ainda está muito longe de ser validado pela educação formal, o que causa para esses sujeitos, um estranhamento e até mesmo certa rejeição, em relação aos processos de aprendizagem desenvolvidos nessas instâncias.

Existe um esforço, hoje em dia, muito válido, diga-se de passagem, de enaltecer as características educativas da capoeira. Destacamos, por exemplo, a capacidade dessa manifestação de trabalhar com valores humanos e permitir a inserção social de jovens excluídos e marginalizados.

Antes de prosseguirmos, e para efeito de melhor compreensão dos conceitos aqui utilizados, cabe-nos definir educação formal, informal e não-formal, entre os autores que se dispõem a discutir o assunto, tal qual Almerindo Afonso (2001, p.9), ao afirmar que:

Por educação formal, entende-se o tipo de educação organizada com uma determinada seqüência e proporcionada pelas escolas, enquanto que a designação educação informal abrange todas as possibilidades educativas no decurso da vida do indivíduo, constituindo um processo permanente e não organizado. Por último, a educação não-formal, embora obedeça também a uma estrutura e a uma organização (distintas, porém, das escolas) e possa levar a uma certificação (mesmo que não seja essa a finalidade), diverge ainda da educação formal no que respeita à não fixação de tempos e locais e à flexibilidade na adaptação dos conteúdos de aprendizagem a cada grupo concreto.

Em grande parte dos projetos de educação não-formal desenvolvidos pelos mais diversos tipos de instituições em nosso país, voltados para as populações de baixa renda, a capoeira aparece como uma das atividades que se encontram maior receptividade por parte desse público de crianças e jovens marginalizados. Os resultados obtidos por essas atividades educacio- 
nais envolvendo a capoeira, bem como outras manifestações da cultura popular, são considerados excelentes na opinião da maioria de pedagogos e arte-educadores envolvidos nesses processos, pois permitem que sejam trabalhados valores como a auto-estima, o respeito pelo outro, a solidariedade e a auto-superação, entre outros benefícios.

Porém não podemos esquecer, como bem nos lembra Frederico Abreu (1999), que a capoeira só consegue esse efeito positivo num universo de marginalizados, "porque ela é feita desse veneno". Ou seja, esses elementos da "vadiagem", da "barra pesada", da "desordem" e da "malandragem", que são termos largamente utilizados e que historicamente constituem o éthos presente no universo da capoeira, não podem ser desconsiderados porque são essenciais na condução de um processo educativo envolvendo sujeitos pertencentes às camadas excluídas da população, que têm a possibilidade de uma maior identificação com a abordagem educativa desenvolvida por essas manifestações. São justamente esses elementos que permitem a "sedução pedagógica" e a sensibilização desses jovens, pois são elementos que fazem parte do seu universo cultural e simbólico, do seu cotidiano.

Talvez seja esse o maior ensinamento que a cultura popular possa estar nos disponibilizando e neste momento atual, em que vem se revitalizando em várias partes do mundo, e com isso, revitalizando também as possibilidades de se pensar e agir sobre os processos de educação vigentes em nossa sociedade, a partir de outros ângulos e outras possibilidades. A experiência, os saberes e conhecimentos da cultura popular representam esse manancial no qual a educação formal precisa se "ensopar", como diria o mestre Paulo Freire.

A cultura popular, historicamente, nunca foi tida enquanto um conhecimento legítimo no âmbito dos currículos da educação formal. A forma "folclorizada" como ainda hoje são retratadas as manifestações da nossa cultura popular, nos programas educacionais da maior parte das escolas, sejam elas particulares ou públicas, é um exemplo claro sobre os preconceitos que persistem nesse âmbito, herança de uma racionalidade eurocêntrica, que influencia ainda, a maioria dos programas formais de educação.

Na maioria dos casos, a cultura popular só entra nos programas educacionais por via de atividades relativas a datas especiais 
como o mês do folclore, o dia da consciência negra, as festas juninas, etc., limitando-se a uma abordagem superficial e caricaturada de seus elementos, não se constituindo enquanto saber legitimado e valorizado pela cultura escolar. Essa realidade tem se modificado nos últimos anos, mas os avanços ainda são restritos, pois antes de mais nada é preciso que haja uma mudança na mentalidade de educadores e gestores educacionais, ainda pautada por uma racionalidade objetivista, tal qual analisada e criticada por nós, nos capítulos anteriores.

Os próprios educadores, em sua maioria, têm dificuldade em estabelecer vínculos entre os saberes universais, provenientes da racionalidade acadêmico-científica, com os saberes populares provenientes das culturas tradicionais, que a nosso ver, seria o caminho ideal a ser seguido pela educação formal. A formação desses educadores deveria garantir que houvesse um tratamento privilegiado às questões referentes aos saberes tradicionais populares, enquanto forma e conteúdo dos programas pedagógicos, para que o processo de troca e diálogo com os saberes científicos se desse de forma mais equilibrada e não hierarquizada. Portanto, além das políticas públicas no campo da educação, a formação continuada dos educadores, também deve estar voltada para as experiências produzidas no campo do saber tradicional popular, pois só dessa forma será possível o alargamento da racionalidade e dos paradigmas que predominam nessas instâncias.

Feitas algumas considerações sobre as dificuldades encontradas pela educação formal em considerar e valorizar os saberes provenientes do universo da cultura popular, após termos analisado as várias formas de aprendizagem presentes nesse universo, acreditamos estar possibilitando a abertura de um possível caminho capaz de permitir a ampliação das referências existentes no âmbito da educação formal, a fim de que possam ser estabelecidos canais de comunicação e diálogo entre o saber acadêmico-científico e o saber popular, proporcionando a possibilidade de construção de propostas educacionais concretas que sejam capazes de incluir e validar os saberes e as experiências advindas da cultura popular.

O universo da cultura popular, enquanto um campo extremamente rico e diversificado, em que a oralidade e a ritualidade abrigam saberes dos mais significativos, remete, como já vimos, 
a toda uma ancestralidade onde residem aspectos importantíssimos relacionados à "história não contada" dos derrotados, aos processos identitários das camadas subalternas da nossa sociedade, ao éthos do povo oprimido, enfim, à cultura dos excluídos do nosso país. Infelizmente, esse universo permanece ainda praticamente inexplorado, como uma mata virgem que guarda riquezas, segredos e enigmas, que se mostram vivos e dinâmicos, mas ainda invisíveis aos olhos dos responsáveis por grande parte dos programas envolvendo a educação formal deste país.

A cultura popular representa para Roger Simon e Henry Giroux (1994), não só um contraditório terreno de luta, mas também um importante espaço pedagógico onde são levantadas relevantes questões sobre os elementos que organizam a base da subjetividade e da experiência do aluno. "Situada no terreno do cotidiano, a cultura popular quando valorizada e legitimada no currículo escolar é, em conseqüência disso, apropriada pelos alunos e ajuda a validar suas vozes e experiências".(SIMON; GIROUX, 1994, p.96)

$\mathrm{Na}$ visão dos autores, o discurso dominante ainda define a cultura popular como o que sobra após a subtração da alta cultura, da totalidade das práticas culturais. Ela é vista como o banal e o insignificante da vida cotidiana, e geralmente é uma forma de gosto popular considerada indigna de legitimação acadêmica ou alto prestígio social.

Simon e Giroux (1994, p. 97) afirmam, ainda, que é precisamente quando pedagogia e cultura popular se relacionam, que surge a importante compreensão de tornar o pedagógico mais político e o político mais pedagógico. "A cultura popular e a pedagogia representam importantes terrenos de luta cultural que oferece não apenas discursos subversivos, mas também relevantes elementos teóricos que possibilitam repensar a escolarização como uma viável e valiosa forma de política cultural."

Talvez seja esse o caminho fundamental a ser seguido, se quisermos pensar num projeto de sociedade e de educação que seja libertador, e que possa trazer consigo, além do conhecimento científico, a força e a sabedoria das pessoas simples do nosso país, como um manancial de experiência e humanidade. 


\section{Considerações finais}

A sociedade brasileira representada pelas suas instituições e órgãos oficiais, presa a uma racionalidade herdeira da tradição positivista, colonial e eurocêntrica, ainda não é capaz de dar validade a esses saberes provenientes da cultura popular que permanecem silenciados e ocultados, "produzidos para não existirem" como diz Boaventura de Sousa Santos, para não serem reconhecidos como possuidores de valor, e por isso, destituídos de dignidade.

A educação formal segue essa mesma lógica, e também não é capaz, com raras exceções, de constituir no âmbito de seus programas e projetos pedagógicos, espaços onde os saberes provenientes da cultura popular possam ser tratados com o mesmo status dos conhecimentos provenientes da tradição acadêmica. E quando a cultura popular se faz presente no âmbito da educação formal, é na maioria das vezes, tratada de forma folclorizada, atuando apenas de acordo com o calendário de comemoração de festas e datas especiais.

Essa realidade nos permite levantar um profundo questionamento sobre as reais possibilidades e perspectivas de algum dia, a educação formal poder cumprir o papel de instituição capaz de articular os saberes provenientes de diferentes tradições, sem hierarquias e discriminações, pois a própria natureza da escola formal, dependente que é da estrutura social determinada pelo capitalismo, como também já criticado anteriormente, não teria condições de levar a cabo tal empreitada. Talvez isso só possa ser possível com a substituição do capitalismo por um outro modelo de estrutura social, mais humano e digno, tarefa que esse trabalho aponta como necessária e urgente no sentido da construção de uma sociedade brasileira mais justa e menos excludente.

Nesse sentido é que apontamos para a educação não-formal, como a possibilidade mais viável de colocar em prática um projeto pedagógico capaz de dar voz, sentido e significado aos saberes provenientes da cultura popular, sobretudo quando falamos da imensa massa formada pelas populações excluídas do Brasil. Aî reside, a nosso ver, um campo político de atuação fundamental, com capacidade de intervenção direta nas realidades mais cruéis e desumanas que pauperizam em todos os sentidos, tantos homens, mulheres e crianças que vivem em todas as regiões do 
Brasil. A educação não-formal é, portanto, hoje, em nossa opinião, a possibilidade mais concreta de implantação de projetos pedagógicos que possam atuar diretamente na melhoria da qualidade de vida desses sujeitos, bem como no sentido da sua conscientização política, fator essencial para que esses indivíduos possam adquirir autonomia e emancipação social, na busca de construir uma vida digna para si e para os seus.

A Capoeira Angola, como tantas outras manifestações da cultura popular, é um rico manancial de humanidade, onde muito se aprende sobre a vida e sobre valores fundamentais para a existência humana como a solidariedade, a igualdade, o respeito às diferenças, o compartilhar, o respeito à natureza, a cooperação, o equilíbrio, a humildade, a parceria, entre tantos outros ensinamentos que a sabedoria do nosso povo vem cultivando, preservando e transmitindo de geração em geração ao longo da história do nosso país, resistindo e lutando por manter vivas suas tradições, legado maior de uma ancestralidade que rege suas formas de ser e estar no mundo.

Acreditamos que os saberes presentes numa roda de capoeira, numa roda de samba, e tantas outras "rodas" de saberes que a cultura popular proporciona, onde pessoas se reúnem para parti1har suas alegrias e tristezas, esperanças e sofrimentos, e onde passado, presente e futuro se juntam num momento único de celebração da vida, são o patrimônio maior desse povo que dança, que ri, que canta e que chora, e que mostra com sabedoria, simplicidade e beleza, a arte de estar sempre, apesar de tudo, insistindo em ser feliz.

Popular Culture and Education: a study into Angolan Capoeira

\begin{abstract}
The objective of this paper is to evaluate the forms in which popular culture articulates a vast field of knowledge and wisdom, as well as the ways this knowledge is transmitted through categories we selected as a base for this evaluation, specifically memory, orality, ancestrality, rituality and temporality. To carry out this task, we chose as our field of study Angola Capoeira, an Afro-Brazilian martial art and highly significant cultural manifestation, in an attempt to find its essence and meaning.

KEY WORDS: Popular culture. Angola Capoeira. Non-formal education.
\end{abstract}




\section{Referências}

ABIB, Pedro R. J. Capoeira Angola: cultura popular e o jogo dos saberes na roda. 2004. Tese (Doutorado em Ciências Sociais aplicadas a Educação) - Universidade de Campinas, 2004.

ABREU, Frederico José de. Bimba é Bamba: a capoeira no ringue. Salvador: Instituto Jair Moura, 1999.

BOSI, Ecléa. Cultura e desenraizamento. In: BOSI, A. (Org.). Cultura brasileira: temas e situações. São Paulo: Ática, 1987.

CASTRO JR., Luis Vitor de; ABIB, Pedro R. J.; SANTANA SOBRINO; José. Capoeira e os diversos aprendizados no espaço escolar. Motrivivência, Florianópolis, ano 11, n. 14, p. 159-171, 2000.

HEIDEGGER, Martin. Ser e tempo. Tradução e notas Márcia de Sá Cavalcanti. Petrópolis: Vozes, 1995.

SANTOS, Boaventura de Sousa. A queda do Ângelus Novus: para além da equação moderna entre raízes e opções. Novos Estudos CEBRAP, n. 47, p. 103-124, mar. 1997

. Por uma concepção muticultural de direitos humanos. In: FELDMAN-BIANCO, Bela; CAPINHA, Graça (Org.). Identidades: estudos de cultura e poder. São Paulo: Hucitec, 2000.

SIMON, Roger; GIROUX, Henry. Cultura popular e pedagogia crítica: a vida cotidiana como base para o conhecimento curricular. In: BARBOSA, Antonio Flávio; SILVA, Tomaz Tadeu da (Org.). Currículo, cultura e sociedade. São Paulo: Cortez, 1994.

RIBEIRO, Caroline V. A experiência de pensamento inaugurada em Ser e Tempo de Martin Heidegger. 2000. Dissertação (Mestrado) - Universidade Federal da Paraíba, Centro de Ciências Humanas, Filosofia, Letras e Artes, João Pessoa, 2000. 